\title{
Governança global do clima: proposta de um marco analítico em construção
}

\section{Global Climate Governance: a proposed analytical framework under construction}

\author{
DOI: $10.21530 /$ ci.v11n1.2016.242
}

Cristina Yumie Aoki Inoue ${ }^{1}$

\section{Resumo}

O objetivo deste artigo é propor um marco analítico provisório do processo de governança global do clima. Busca-se um instrumento para descrever e analisar uma realidade, em construção, bem como uma perspectiva que possa contribuir na procura de respostas eficientes, cooperativas, sustentáveis e justas à mudança do clima. Alguns estudiosos têm argumentado a favor de uma perspectiva de análise centrada na noção de governança do clima, ao invés do conceito de regime internacional. Isso se deve a três limites relacionados ao conceito de regimes internacionais ${ }^{2}$ : o status proeminente do estado-nação, a sua natureza definida como unitária (caixa-preta) e a diferenciação e forte demarcação como duas arenas políticas separadas: a doméstica e a internacional. Outros consideram que regimes internacionais são subsistemas de governança. Este artigo argumenta que a noção de governança é mais ampla e por isso compreende mais dimensões do fenômeno. Não existe, no entanto, uma definição consensual de governança global, tampouco de governança climática. Propõe-se aprofundar a discussão conceitual sobre governança climática, enquanto uma problemática multidimensional, que interliga economia-política, segurança, meio ambiente e energia e que engloba múltiplas escalas, níveis e atores.

Palavras-chave: Governança global do clima, mudança do clima, regimes internacionais, limites planetários.

1 Professora do Instituto de Relações Internacionais da Universidade de Brasília, Doutora em Desenvolvimento Sustentável.

Artigo recebido em 25/09/2015 e aprovado em 08/05/2016.

2 A definição de regimes internacionais de Krasner não restringe os atores a estados-nacionais, nem pressupõe a divisão rígida entre política doméstica e internacional. A crítica de Okereke et al. (2009) se refere às análises empíricas de regimes internacionais, que têm prevalecido na literature. 


\begin{abstract}
This article aims at constructing an analytical framework for the process of global climate governance. The attempt is to have an instrument to describe and analyze a reality that is under construction. It also aims at contributing in the search for efficient, cooperative, sustainable and fair responses to climate change. Some scholars have argued for perspectives based on the notion of climate governance, instead of the concept of international regime for which they identify three limits: the prominent status of the national state, its unitary nature and the strong demarcation between the domestic and international arenas. Other authors consider international regimes as governance sub-systems. This article argues that the notion of governance is wider and thus can encompass more dimensions of the phenomena. However, there is no consensual definition of global governance, neither of climate governance. Therefore, the article proposes a conceptual discussion of climate governance, that is multidimensional and connects political-economy, security, environment and energy, encompassing multiple scales, levels and actors.
\end{abstract}

Keywords: Global climate governance, climate change, international regimes, planetary limits

\title{
Introdução
}

Vivemos um descompasso entre as evidências científicas sobre as mudanças ambientais globais e a capacidade das sociedades de responderem a essas mudanças, no sentido de evitá-las ou minimizá-las, ou mesmo de se prepararem para lidar com suas consequências. O crescimento exponencial das atividades humanas aumenta cada vez mais a pressão sobre os sistemas planetários o que poderia desestabilizar sistemas biofísicos e gerar mudanças ambientais abruptas ou irreversíveis, deletérias ou até catastróficas para o bem-estar humano (RÖCKSTROM et al., 2009). Os autores denominam de fronteiras planetárias (limiares planetários) os contornos de um espaço de operação seguro para a humanidade, que não devem ser ultrapassados, tendo em vista os riscos que a humanidade enfrenta na transição planetária do Holoceno para o Antropoceno³.

De acordo com Röckstrom et al. (2009), as atividades humanas crescentemente influenciam o clima da Terra e seus ecossistemas. Os autores identificaram nove processos para os quais fronteiras devem ser estabelecidas para minimizar o risco de ultrapassar limiares críticos ${ }^{4}$, que podem levar a resultados indesejáveis.

3 Antropoceno é considerado uma nova época geológica em que o motor dominate de mudanças dos sistemas do Planeta Terra são os seres humanos (Crützen 2002; Steffen et. al. 2007 apud RÖCKSTROM et al. 2009).

4 No original em inglês: critical thresholds. 
Essas fronteiras planetárias cobrem ciclos biogeoquímicos do nitrogênio, fósforo, carbono e água; os sistemas principais de circulação física do planeta (o clima, a estratosfera e os oceanos); características biofísicas da Terra, que contribuem para a resiliência subjacente de sua capacidade de autorregulação (biodiversidade marinha e terrestre, sistemas terrestres); e duas características críticas associadas com a mudança global antropogênica (sobrecarga de aerossol e poluição química).

Entre esses, a mudança global do clima é um dos processos de escala planetária identificados por Röckstrom et al. (2009), que produzem impactos subsistêmicos de cima para baixo. Os autores apontam para evidências como a diminuição da camada de gelo do oceano Ártico e dos picos gelados ao redor do mundo, perda da cobertura de gelo da Groenlândia e do oeste antártico, a elevação do nível do mar nos últimos 10 a 15 anos, entre outras. Além disso, ressaltam que o clima contemporâneo está saindo do "envelope" da variabilidade do Holoceno de forma aguda, o que aumenta o risco de mudança climática perigosa.

O objetivo geral desse artigo é apresentar e discutir o conceito de governança global do clima como caminho para analisar as respostas coletivas à problemática da mudança global do clima. Mais especificamente, pretende-se construir um marco analítico provisório, porque sempre em construção, para estudar o processo de governança, entendido como construção de instituições e políticas para responder às mudanças do clima global.

A ênfase na mudança global do clima se justifica por ser considerada um vetor civilizatório (VIOLA, FRANCHINI, RIBEIRO 2013). Tal problemática é um dos maiores desafios de governança contemporâneos, talvez mais complexo do que o risco da hecatombe nuclear durante a Guerra Fria, por envolver múltiplas dimensões, setores e atores das relações internacionais, permeando as questões de segurança e economia política. Viola, Franchini e Ribeiro (2013, p. 25-26) a consideram um vetor civilizatório, ou seja, os autores promovem o clima, enquanto categoria social, ao mesmo patamar de dois outros processos: globalização e democracia. Esses processos, ao lado do clima, são considerados centrais para entender a evolução das sociedades contemporâneas. Viola, Franchini e Ribeiro (2013) reconhecem na problemática do clima uma fronteira planetária fundamental, que, segundo Röckstrom et al. (2009), já foi ultrapassada e, por isso, constitui-se como um tema em que, paradoxalmente, cresce o abismo entre ciência e política.

Em relação ao objetivo de explorar o conceito de governança, justifica-se pelo descompasso mencionado acima e também por estudos como o de Biermann et al. (2012), que apontam para a necessidade de uma reestruturação e reorientação 
fundamental das instituições nacionais e internacionais em direção a uma governança dos sistemas da Terra ${ }^{5}$. No artigo escrito por ocasião da Rio +20 , os autores avaliam que prevalecem diferenças de opinião entre cientistas sociais, da mesma forma que há consensos crescentes em muitas áreas. A conclusão geral é de que mudanças incrementais, como as que têm ocorrido desde 1972, não são mais suficientes para trazer a transformação societária no nível e velocidade necessários para mitigar e adaptar-se à transformação dos sistemas da Terra. Por isso, é necessária uma mudança estrutural na governança global (BIERMANN et al. 2012) ${ }^{6}$.

Alguns estudiosos têm argumentado a favor de uma perspectiva de análise centrada na noção de governança do clima, ao invés do conceito de regime internacional. Conforme será discutido, este artigo segue a visão de Rosenau (1992) de que a governança é um processo mais amplo do que o abarcado no regime internacional, não havendo oposição entre os conceitos. Não existe, no entanto, uma definição consensual de governança global, tampouco de governança climática. Desse modo, pretende-se aprofundar a discussão conceitual sobre regimes internacionais e governança climática, buscando avaliar sua adequação à análise dos desafios trazidos pela mudança global do clima, enquanto uma problemática multidimensional que interliga economia política, segurança, meio ambiente e energia, e que engloba múltiplas escalas, níveis e atores. Ressalta-se, ainda, que a questão da governança, além de se relacionar a diferentes teorias e agendas de pesquisa, remete a projetos normativos, ou empreendimentos políticos de diferentes atores, o que pode gerar distorções. O foco deste estudo é a dimensão analítica da noção de governança.

Para discutir a governança global do clima e identificar elementos para a construção de um marco analítico, será realizada uma breve revisão da literatura corrente sobre governança com vista a apontar as possibilidades analíticas do conceito. Almeja-se, assim, identificar um marco conceitual (provisório) para descrever e analisar um processo, em construção, bem como desenvolver uma perspectiva que possa contribuir na busca por respostas eficientes, cooperativas, sustentáveis e justas à mudança do clima. Dado o estado da arte da pesquisa empírica, ainda não é possível desenvolver o que seria um "tipo ideal” de governança climática global, que seria útil do ponto de vista analítico-empírico e normativo. Desse modo, este artigo localiza-se num estágio preliminar de desenvolvimento conceitual ao

5 Earth System Governance, no original em inglês.

6 Entretanto, os autores se limitaram a propor a criação de uma organização mundial ambiental. 
propor dimensões, processos e mecanismos que devem ser considerados na análise. Trata-se apenas de um marco analítico em construção.

O artigo é dividido em três partes: na primeira, discutem-se os conceitos de regime internacional e de governança; na segunda, identificam-se três dimensões analíticas de uma abordagem de governança global do clima. Assim, consideram-se questões de poder e escalas; relação agente-estrutura, atores e agentes, além disso, identificam-se processos de governança e novos mecanismos, com foco em tipos de arquitetura, redes e governança policêntrica. Por último, são tecidas algumas conclusões sobre as possibilidades analíticas do conceito, bem como sobre os desafios normativos, decorrentes do descompasso entre a urgência apontada pela ciência e a falta ou inadequação das respostas à problemática da mudança global do clima.

\section{Governança como perspectiva analítica: para além da análise de regimes internacionais?}

Na literatura em Relações Internacionais e meio ambiente, até meados da primeira década dos anos 2000, têm prevalecido abordagens centradas nas análises de regimes internacionais (VIOLA, FRANCHINI, RIBEIRO 2013). Regimes internacionais podem ser considerados instituições sociais criadas para responder à necessidade de governança em áreas temáticas específicas, que surgem num cenário anárquico (BREITMEIER, YOUNG, ZURN 2006). Para Levy, Young e Zürn (1995, p. 274) regimes internacionais ambientais são instituições sociais constituídas de princípios, normas, regras, procedimentos e programas que governam as interações dos atores em áreas temáticas específicas. Wettestad (1999) também adota esta última definição, que é muito próxima àquela adotada por Krasner (1982), diferenciando-se apenas pela afirmação de que regimes são instituições sociais. Breitmeier, Young e Zurn (2006, p. 9) realizam ampla revisão dos estudos sobre regimes internacionais e constatam que a maioria da pesquisa sobre regimes emprega métodos qualitativos e mais frequentemente dão atenção para desenvolvimento de estudos de caso.

Por meio de um amplo levantamento da literatura, Breitmeier, Young e Zurn (2006) apontam que alguns analistas realizam estudos minuciosos de regimes internacionais específicos para desenvolver argumentos mais amplos, conceituais e teóricos, sobre a formação e operação de instituições na sociedade internacional. As questões e conceitos identificados por Breitmeier, Young e Zurn (2006) nessa 
literatura compreendem: comunidades epistêmicas, papel dos discursos e brokers de conhecimento, ou das avaliações científicas na criação e implementação de regimes internacionais; hipóteses sobre formação e efetividade de regimes e sobre mecanismos por meio dos quais esses influenciam o comportamento; tipologias de problemas internacionais - benignos ou malignos -, entre outros (BREITMEIER, YOUNG, ZURN 2006).

Com base na revisão dos estudos realizada, Breitmeier, Young e Zurn (2006) chamam a atenção para características comuns dos regimes internacionais. Ainda que todos sejam motivados por problemas e digam respeito a uma área específica ${ }^{7}$, tais estudos revelam discordância sobre a relevância dos problemas e sobre as formas de solucioná-los. Embora se reconheça a emergência de vários atores não estatais como forças motoras no nível internacional e transnacional, a maioria dos estudos enfatiza a sociedade de estados, ou o sistema interestatal. Assim, os membros dos regimes são estados e as regras, associadas à ideia de soberania.

O conceito de governança, tal qual trabalhado na literatura, é mais amplo do que o de regime internacional, mas certamente relacionado a esse. Como exposto por Rosenau, a definição mais amplamente aceita de regimes configura-se com base na limitação temática. Ou seja, essa visão considera os componentes e a concordância intersubjetiva dos atores em torno de áreas temáticas ${ }^{8}$ (ROSENAU, 2000, p. 21-22.). Governança global estaria, portanto, relacionada à ordem global, inclusive abarcando a sobreposição, interação ou conflito entre dois ou mais regimes internacionais. Ademais, as fronteiras entre áreas podem, por vezes, ser artificiais e inadequadas (INOUE; PRADO, 2006).

O foco temático tem sido importante para o desenvolvimento dos estudos sobre regimes. Há uma ampla literatura que tem desenvolvido conceitos e levantado hipóteses, como apontado por Breitmeier, Young e Zurn (2006). Entretanto, o foco numa área específica também pode se tornar um limite, principalmente se reduzir o escopo de análise apenas a alguns instrumentos jurídicos internacionais ou a alguns atores, como os estados. A mudança global do clima se configura como um tema multissetorial, que não se restringe mais à dimensão ambiental e perpassa as dimensões econômica e de segurança (VIOLA, FRANCHINI, RIBEIRO 2013; PAINEL BRASILEIRO DE MUDANÇAS CLIMÁTICAS, 2014).

7 No original em inglês: problem-driven - issue-specific.

8 No original em ingles: issue areas. 
Keohane e Victor (2010) buscam ir além do foco num único regime para tratar a questão climática e utilizam o conceito de complexo de regimes desenvolvido por Raustiala e Victor (2004, p.295). De acordo com Keohane e Victor (2010), o complexo de regimes situa-se numa posição intermediária de um contínuo, que se inicia, de um lado do espectro, por instituições internacionais abrangentes focadas num único instrumento legal integrado e, do outro lado, por arranjos altamente fragmentados. Dessa forma, entre os dois extremos estão regimes aninhados e complexos de regimes, que são conjuntos frouxamente agrupados de regimes específicos.

O complexo de regimes do clima compreende as instituições criadas no âmbito da Convenção-Quadro das Nações Unidas sobre Mudança do Clima (UNFCCC), iniciativas de grupos ou clubes de países, como a Asian Pacific Partnership (APP), o Major Emitters Forum (MEF), o G8 ou o G20, bem como iniciativas bilaterais. Abrange, ainda, o Intergovernmental Panel on Climate Change (IPCC), outros regimes regionais, ou internacionais, regulatórios de outros gases, como o ozônio (Convenção de Viena/Protocolo de Montreal) ou poluentes como o carbono negro (black carbon), os quais, quando controlados, têm efeito positivo, por isso, são sinérgicos à mitigação da mudança do clima. Além disso, consideram o Banco Mundial, tanto pelo seu aspecto de financiador de iniciativas ligadas ao regime da UNFCCC - por exemplo, o mecanismo de desenvolvimento limpo ou o Global Environmental Facility -, como pela possibilidade de incentivar ou constranger investimentos, benéficos ou maléficos ao clima global. Ações unilaterais de atores subnacionais, ou da indústria, também são apontadas como parte do complexo (KEOHANE; VICTOR 2010).

Embora o conceito de complexo de regime do clima permita ir além da análise de um único regime, ainda deixa em aberto questões importantes relativas a agência, níveis de análise e escala. Estudiosos têm apontado para os limites na abordagem de regimes internacionais. Okereke et al. (2009) questionam o foco estatocêntrico, no que diz respeito ao status proeminente do estado, sua natureza, definida como unitária (caixa-preta), além da diferenciação e forte demarcação de duas arenas políticas separadas: a doméstica e a internacional (OKEREKE et al., 2009, p. 59). Nesse sentido, a análise de regimes internacionais tem se concentrado menos em variáveis domésticas e mais em fatores sistêmicos. Assim, a maioria dos estudos tem focado o papel dos estados, deixando de lado o papel de outros atores, com algumas exceções, como, por exemplo, o conceito de comunidades epistêmica 
(HAAS, 1992), que revela atuação das redes transnacionais de especialistas na formação dos regimes.

Bulkeley e Newell (2010, p. 2) argumentam que a complexidade da governança da mudança do clima resulta de três fatores inter-relacionados: as múltiplas escalas de processo decisório; os papéis fragmentados e mesclados de atores estatais e não estatais; a natureza profundamente imbricada de muitos dos processos de que se originam as emissões de gases de efeito estufa. Consequentemente, a abordagem da governança contribui ao ir além do foco numa única área temática e da separação entre as arenas políticas. Além disso, abre a possibilidade de considerar o papel de outros atores.

Na compreensão de Stokke, com base no trabalho de Young, governança seria o "estabelecimento e operação de regras de conduta que definem práticas, designam papéis e guiam a interação para lidar com problemas coletivos” (STOKKE, 1997, p. 28). A governança global aborda os criadores e operadores dessas regras como sendo também atores não estatais de vários tipos, tanto transnacionais quanto subnacionais. Portanto, a visão sobre governança global relativiza a assertiva sobre a unicidade e racionalidade dos atores envolvidos (INOUE; PRADO, 2006).

Governança e governança global têm sido definidas de diversas formas (ROSENAU, 1992; COMMISSION ON GLOBAL GOVERNANCE, 1995; HELD et al., 1999; YOUNG, 2000; PATERSON; HUMPHREYS; PETTIFORD, 2003; HAAS; SPETH, 2006). Não existe ainda uma definição consensual, porém, todas trazem um sentido de direcionamento e objetivos coletivos. Muitos autores consideram o papel de atores estatais e não estatais e as múltiplas escalas. Held et al. (1999, p. 50) consideram governança global como as instituições e organizações formais por meio das quais as regras e normas que governam a ordem mundial são (ou não) elaboradas e sustentadas (instituições estatais, cooperação intergovernamental etc.), bem como aquelas organizações e grupos de pressão - de corporações multinacionais, movimentos sociais transnacionais à multiplicidade de organizações não governamentais (ONGs) - que buscam objetivos e metas que se relacionam, em alguma medida, com regras transnacionais e sistemas de autoridade.

Para Rosenau (2000), governança se refere a comportamentos que visam objetivos, a atividades orientadas para metas e a sistemas de ordenação, ou seja, um conjunto de atividades apoiadas em objetivos comuns, que podem, ou não, derivar de responsabilidades legais e formalmente prescritas. Esse conjunto não depende necessariamente da existência de um governo, entendido como 
autoridade formal. Trata-se de um fenômeno mais amplo do que o governo. Segundo Young (2000), a governança não pressupõe a necessidade de criar entidades, ou organizações, mas envolve o estabelecimento e operação de instituições sociais, entendidas como conjuntos de regras, procedimentos de tomada de decisão e atividades programáticas que servem para definir práticas sociais e para guiar as interações daqueles que participam dessas práticas.

Na mesma linha, Bulkeley (2005) parte de uma perspectiva de que as relações sociais têm uma dimensão de redes, por isso, utiliza uma interpretação ampla do termo governança, com um foco em sistemas de condução em que atores estatais não são necessariamente os únicos ou os participantes mais significativos. A autora não considera governo e governança como opostos, mas um contínuo de sistemas de governar em que atores estatais e não estatais desempenham uma variedade de papéis. Consequentemente, Bulkeley enfatiza configurações de governança que são híbridas, envolvem uma mistura de atores estatais e não estatais e se realizam em múltiplas escalas, incluindo, assim, simultaneamente, atores oriundos de níveis diferentes de organização social (BULKELEY, 2005, p. 881).

Desse modo, governança não apenas inclui atores diversos, como múltiplos níveis de organização da sociedade. Uma outra perspectiva interessante é aquela adotada pelo Projeto Earth System Governance ${ }^{9}$ (ESG). Bierman (2007) argumenta que o ESG, como um projeto de pesquisa acadêmica, encontra-se na interface entre a earth system analysis e as teorias de governança e reúne as ciências sociais, que analisam as respostas humanas organizadas frente às transformações dos sistemas do planeta Terra, em particular instituições e agentes que causam a mudança ambiental global e as instituições em todos os níveis, que são criadas para dirigir o desenvolvimento humano de uma forma, que assegure uma coevolução segura com processos naturais.

Biermann et al. (2009) apontam que o Earth System Governance pode ser considerado um fenômeno social, um programa político e um tema de pesquisa composto de vários recortes. Como fenômeno, pode ser entendido como

o sistema de regras formais e informais inter-relacionadas e cada vez mais integradas, sistemas de formulação de regras e redes de atores em todos os níveis da sociedade humana (do local ao global) que são desenvolvidos para guiar sociedades para a prevenção, mitigação e adaptação a mudanças ambientais

9 Conferir em < http://www.earthsystemgovernance.org/ > , acesso 01 de outubro de 2010. 
locais e globais, particularmente, a transformação do sistema terrestre, no contexto normativo do desenvolvimento sustentável. A noção de governança refere-se, aqui, a formas de direcionamento que são menos hierárquicas do que a tradicional forma governamental de elaboração de políticas (ainda que a maior parte dos arranjos modernos de governança também inclua algum grau de hierarquia), mais descentralizadas, abertas à auto-organização e à inclusão de atores não estatais que vão desde indústrias e organizações não governamentais até cientistas, comunidades locais, governos municipais e organizações internacionais. (BIERMANN et al. 2009) ${ }^{10}$

Dessa forma, a noção de governança é mais abrangente para tratar o amplo conjunto de respostas e as tentativas de lidar com a mudança global do clima a partir de múltiplos atores, setores e níveis de análise, buscando identificar interações entre economia, ambiente e segurança. Essa não exclui o conceito de regimes internacionais (ROSENAU, 2000), mas abre o escopo da análise para incluir outros atores e relações além dos estados e não se limita a uma esfera singular (ROSENAU, 2000). Biermann, Pattberg e Zelli (2010, p. 1) identificam três elementos centrais do conceito de governança global que demarcam a diferença em relação à política intergovernamental tradicional. Primeiro, a emergência de novos atores para além dos governos centrais, que criam um novo contexto político com novas constelações de atores e relações de poder. Segundo, o surgimento de novos mecanismos de estabelecimento e de implementação transnacionais de regras, que vão além do domínio da cooperação intergovernamental, como, por exemplo, regimes transnacionais, parcerias público-privadas e arranjos com base no mercado. Terceiro, novos tipos de fragmentação vertical e horizontal e interconexões na política mundial, que requerem novos entendimentos.

Em seguida, busca-se identificar algumas dimensões, que, em conjunto, podem compor um marco conceitual para tratar a problemática da governança do clima. Trata-se da tentativa de construir um caminho analítico que considere as relações de poder, diversos atores, múltiplos níveis de escala de ação e de organização social, bem como novos mecanismos e arranjos institucionais.

10 The interrelated and increasingly integrated system of formal and informal rules, rule-making systems, and actor-networks at all levels of human society (from local to global) that are set up to steer societies towards preventing, mitigating, and adapting to global and local environmental change and, in particular, earth system transformation, within the normative context of sustainable development. The notion of governance refers here to forms of steering that are less hierarchical than traditional governmental policy-making (even though most modern governance arrangements will also include some degree of hierarchy), rather decentralized, open to self-organization, and inclusive of non-state actors that range from industry and non-governmental organizations to scientists, indigenous communities, city governments and international organizations. 


\section{Dimensões analíticas do conceito de governança global do clima}

Propõem-se aqui um marco analítico-conceitual que identifica dimensõeschave na análise dos processos envolvidos na governança global do clima. A partir da literatura, discutem-se questões relativas às relações de poder e escalas; atores e agentes e relação agente-estrutura; tipos de arquitetura e arranjos de governança. Esses elementos de análise estão em consonância com o proposto por Biermann, Pattberg e Zelli (2010), que enfatizam a dimensão analítica da noção de governança global e identificam as três tendências mencionadas acima: emergência de novos tipos de agência e de atores, além dos governos nacionais; surgimento de novos mecanismos e instituições de governança ambiental global, que vão além das formas tradicionais de regimes liderados por estados e baseados em tratados; e a crescente fragmentação e emergência de interligações de sistemas abrangentes de governança através de níveis e esferas funcionais.

Bulkeley e Newell (2010, p. 2-3) afirmam que o entendimento limitado da natureza global da mudança do clima resultou no foco restrito à dimensão internacional, pois são os estados que assinam acordos e participam de instituições internacionais. Porém, eles argumentam que se deve pensar o global como uma categoria causal, ao invés de espacial, o que leva a um ponto de partida diferente para pensar quem governa a mudança do clima e onde a governança acontece. Além disso, os autores consideram que se têm negligenciado outras escalas dos processos decisórios, que moldam as trajetórias das emissões de gases estufa e o potencial de adaptar-se à mudança do clima. Desse modo, concebem a mudança do clima como um problema multinível, em que diferentes níveis de tomada de decisões (local, regional, nacional e internacional), novas esferas e arenas de governança, que perpassam fronteiras, estão envolvidas na criação e na busca de soluções da mudança climática.

O argumento de Bulkeley e Newell (2010) vai ao encontro da constatação de que o processo de governar a mudança do clima resultou não apenas na participação de um amplo conjunto de atores (de indivíduos, por meio de comunidades locais, a organizações transnacionais), mas na emergência de arranjos relativamente novos de governança em todos os níveis de organização social, incluindo coalizões de governos subnacionais, redes transnacionais, parcerias público-privadas, arranjos privados (OKEREKE et al., 2009, p. 65-66). Assim, a própria natureza do estado e a forma como ele alcança resultados, bem como a fronteira entre autoridade pública e privada, são questionadas (idem, p. 66). Dessa forma, 
é importante identificar questões-chave para entender a governança do clima de forma analítica.

\section{Relações de poder e escalas}

Okereke et al. (2009, p. 59) identificam questões que precisam ser exploradas para se desenvolver um entendimento mais robusto da governança global do clima: a natureza do poder na governança global, a relação entre autoridade pública e privada, dinâmicas entre estrutura e agência, as racionalidades e processos reais de governança (teorias neo-gramscianas e de governamentalidade foucaultiana).

Nesse sentido, esses autores propõem que se devem buscar noções alternativas de poder e autoridade e prestar atenção nas questões de quem e o que estão envolvidos em governança (OKEREKE et al., 2009, p. 61-63). Assim, defendem uma concepção de poder em termos múltiplos e relacionais, ou seja, não apenas o papel de outros grupos de atores em influenciar atores estatais, mas atores como "governadores" em si mesmos. O poder seria, assim, "compartilhado" entre atores, ou localizado em múltiplos lócus. Isso implica conceber poder em termos constitutivos, relativo à organização da sociedade, estado e mercado. Além disso, ao considerar a natureza múltipla do poder, os autores distinguem, analiticamente, soberania e governo como formas distintas de poder. Soberania diz respeito ao controle sobre um território e ao uso de sanções e do estado de direito como meio de impor ações. Governo compreende a totalidade de mecanismos, técnicas e procedimentos específicos que autoridades políticas dispõem para realizar e colocar em prática programas (MACKINNON, 2000, p. 295 apud OKEREKE, 2009, p. 63).

Desse modo, Okereke et al. (2009) combinam duas abordagens distintas: referem-se a Foucault para ressaltar que governo seria uma forma de poder sobre populações, ao invés de territórios, ou seja, conjuntos de instituições, procedimentos, análises e reflexões, cálculos e táticas, que permitem o exercício dessa forma específica e complexa de poder. Recorrem, também, a uma abordagem neo-gramsciana (OKEREKE, 2009, p. 63) para chamar a atenção para formas através das quais conhecimento e poder se constituem mutuamente para elevar atores específicos, políticas e práticas que privilegiam uma racionalidade particular na governança. Assim, ao reconhecer a natureza múltipla e relacional de poder, Okereke et al. (2009, p. 65) não atribuem aos atores medidas de poder e resultados políticos previsíveis, mas consideram fatores sociais e políticos múltiplos e dinâmicas que conferem aos atores medidas variadas de poder em diferentes estágios. Consideram, ainda, a possibilidade de relações desiguais de poder e interesses conflitantes, 
que podem existir mesmo quando atores, ou grupos de atores, afirmam que estão agindo em consenso. Por último, reconhecem que a influência dos atores não é simplesmente uma questão de onde tais atores se posicionam em termos de políticas e programas específicos de clima, mas também de onde eles se posicionam em relação a outros atores.

Ao considerar a governança do clima como um fenômeno fragmentado e que ocorre em múltiplas escalas, é preciso estar atento às relações de poder e como escalas são social e historicamente construídas. A capacidade de controlar e capturar recursos de níveis e escalas diferentes reflete e reproduz relações de poder. Além disso, escalas e níveis em que um problema é vivenciado, analisado e discutido podem não corresponder a escalas e níveis dos órgãos de tomada de decisão (TOWERS, 2000 apud LEBEL; GARDEN; IMAMURA, 2005). Nesse sentido, atores podem contestar escalas e níveis e mudar questões para outras escalas e níveis em que eles são mais influentes, ou têm mais poder. (LEBEL; GARDEN; IMAMURA, 2005). Os autores chamam a atenção para o que denominam "state simplification" (SCOTT, 1998 apud LEBEL; GARDEN; IMAMURA, 2005), que ocorre quando estados apelam para interesses mais amplos para simplificar sistemas locais diversos e usam sistemas unificados para racionalizar o planejamento do desenvolvimento e a gestão ambiental. Tentam, assim, simplificar e encaixar pessoas, instituições, paisagens nos níveis e escalas dos sistemas estatais de contabilidade e monitoramento. Essa observação é fundamental quando se consideram as múltiplas fontes de emissões de gases de efeito estufa e como estabelecer políticas para mitigar a mudança do clima, considerando as diferenças entre os níveis local, nacional e internacional.

Na mesma direção, Gupta (2007) ressalta que, ao se enquadrar problemas em níveis específicos, em diferentes escalas, os contornos dos problemas mudam e, consequentemente, mudam também as soluções que são relevantes. Nesse sentido, é preciso atentar para como processos de definição de escala e níveis estão interligados com disputas por dominação e controle (BULKELEY, 2005), pois formas diferentes de governança hierárquica, ou em rede, interagem e intersectam para produzir formatos, mecanismos e resultados específicos de governança (BULKELEY, 2005). A autora chama a atenção para o que ela denomina "geografias de governança”, que implicam mudanças no lócus da autoridade na política global: "política de escala é um elemento chave no entendimento na natureza do Estado e sua autoridade, e consequentemente para a natureza da governança ambiental."11 (BULKELEY, 2005, p. 883).

11 Politics of scale is a key element in understanding shifts in the nature of the state and its authority, and hence for the nature of environmental governance. 
De acordo com Lebel et al. (2005), a metáfora "politics of scale" se refere a situações onde atores diferentes contestam a extensão e resolução espaciais da informação e das decisões, e as contrastam com a "politics of place and position". Esta última ("politics of position") remete às relações de poder entre localizações e depende da posição física relativa, por exemplo, as relações entre usuários de um rio a montante e a jusante, ou de margens diferentes. A primeira ("politics of place") se refere aos desdobramentos das relações de poder entre stakeholders, as quais emergem por causa das características especiais dos lugares, interagindo acima e além daquelas que surgem dos níveis ou da posição.

Desse modo, as relações de poder na governança global do clima não podem ser pensadas desvinculadas dos lugares e posições dos atores envolvidos. Embora a mudança do clima e os problemas ambientais em geral sejam globais, as soluções envolvem diferentes atores, em escalas diferenciadas e diversos níveis de tomada de decisão. Bulkeley (2005) nos lembra que os conceitos de espaço e escala não devem ser considerados sinônimos de "contêineres territoriais", no interior dos quais acontece a vida social e política, de tal forma que os níveis de tomada de decisão são vistos como se fossem independentes e as decisões consideradas como uma cascata que parte do nível internacional, descendo ao nacional até chegar ao local (ADGER et al., 2003 apud BULKELEY, 2005; BULKELEY; BETSILL, 2003; OWENS, 2004 apud BULKELEY 2005).

É fundamental considerar como as escalas espacial, jurisdicional e temporal interagem e influenciam as relações de poder no processo da governança da mudança climática global. As ações de atores em determinados espaços, jurisdições e tempos afetam outros atores em outros espaços, jurisdições e tempos. Além da complexidade científica e tecnológica do problema do clima, o processo de definição das responsabilidades e soluções envolve relações de poder entre os atores, que ocupam espaços e jurisdições diferentes, além dos atores em potencial num tempo futuro.

\section{Relação agente-estrutura, atores e agentes}

Outro limite da abordagem de regimes internacionais é não atentar para o papel da estrutura, que é entendida em sentido amplo para incluir estrutura geral de poder e as regras, normas e princípios individuais, que moldam a política global (OKEREKE et al., 2009, p. 68-69). Okereke et al. (2009) consideram a perspectiva neo-gramsciana de que, embora as estruturas não determinem os resultados, elas 
definem o conjunto potencial de estratégias alternativas entre as quais os agentes podem escolher. No entanto, elas não são imutáveis, pois podem ser transformadas pelos agentes. A agência é localizada na estrutura, mas não determinada por essa, ou seja, a interação social é condicionada, mas não estruturalmente determinada (idem, p. 69). Trata-se de reconhecer a natureza mutuamente constitutiva da relação agente-estrutura. Forças estruturais determinam uma série de opções disponíveis num contexto histórico, mas as estruturas dependem do acúmulo de decisões dos atores para sua criação e perpetuação (STEANS, 2004).

Em resumo, são múltiplos os agentes da governança global do clima. Estes são condicionados, porém, e não determinados pelas estruturas de poder. Por isso, ao formarem novos arranjos de governança, criam possibilidades de mudanças. Avant Finnemore e Sell (2010) definem que os agentes, ou "governadores globais", são autoridades que exercem poder através das fronteiras para afetar políticas. Para elas, há cinco fontes de autoridade: institucional, delegada, expertise, baseada em princípios, baseada em capacidades (AVANT; FINNEMORE; SELL 2010, p. 10). Dellas, Pattberg e Betsill (2011) afirmam que agentes são aqueles que desempenham atividades de governança e o consentimento não é a única fonte de autoridade e legitimidade, assim, a agência é baseada na capacidade de indivíduos e atores coletivos de mudar o curso dos eventos, ou o resultado de processos, desde que tal capacidade se baseie em autoridade e não na força (PATTBERG; STRIPPLE, 2008, p. 273-274 apud DELLAS; PATTBERG; BETSILL 2011, p. 87).

Para facilitar as análises empíricas, é preciso delimitar o que fazem os agentes e indicar formas de como avaliar suas ações. Avant, Finnemore e Sell (2010, p. 14-16) definem algumas tarefas, ou atividades implícitas, realizadas pelos agentes (governadores) no processo de governança: estabelecimento de agendas e criação de questões ${ }^{12}$, elaboração de regras, implementação e imposição ${ }^{13}$, monitoramento e adjudicação. Assim, "governadores globais" desempenham uma combinação dessas atividades políticas ${ }^{14}$, que produzem ação coordenada na ausência de governo mundial.

Além de identificar as tarefas, é importante avaliar o grau de envolvimento e participação nas tarefas. Schroeder (2010) diferencia atores de agentes de governança. Os atores podem ser indivíduos, organizações e redes, que somente participam dos processos decisórios, porém, um agente é um ator que é capaz de

12 No original em inglês: issue.

13 No original em inglês: enforcement.

14 No original em inglês: policy making. 
prescrever comportamentos e obter consentimento dos governados, ou seja, pode diretamente moldar resultados (SCHROEDER 2010, p. 319-320). A autora constrói uma tipologia que reconhece graus variados de agência, de acordo com tipos de envolvimento em tarefas de governança.

\section{Quadro 1: Tipologia de agência}

\begin{tabular}{|l|l|}
\hline Tipos de envolvimento no processo de políticas internacionais & Graus de agência \\
\hline (1) ser informado de fatos e resultados & Nenhum \\
\hline $\begin{array}{l}\text { (2) ser consultado ou convidado a prover input ou feedback } \\
\text { e preocupações serão refletidas nos resultados }\end{array}$ & Fraco e indireto \\
\hline $\begin{array}{l}\text { (3) ser envolvido como um parceiro júnior, com garantias de que visões } \\
\text { (4) senvidado a colaborar em bases iguais }\end{array}$ & Forte mas indireto \\
\hline (5) ser empoderado e ter autoridade de decisão & Fraco mas direto \\
\hline
\end{tabular}

Fonte: INOUE, 2012, com base em Schroeder ${ }^{15}$ (2010, p. 322) and International Association for Public Participation IAP2 2007) ${ }^{16}$

Em resumo, para analisar o processo de governança global do clima é importante identificar os atores e agentes, as atividades desempenhadas e reconhecer que a agência deve ser considerada não em termos absolutos, mas em graus. Reconhecer que o estado não é o único agente, nem um ente unitário, e que a governança global do clima envolve múltiplos atores, agentes e escalas, aponta para novos mecanismos de governança e formas de cooperação, ao lado do sistema tradicional de acordos legalmente vinculantes negociados por estados (BIERMANN; PATTBERG; ZELLI, 2010, p. 9). São arranjos diversos, envolvendo atores públicos e privados. Além disso, deve-se lembrar que do argumento de Biermann et al (2010, p. 15) de que as arquiteturas de governança global do clima são sempre, em algum grau, fragmentadas, e a questão-chave é saber que tipos de arquiteturas prometem um grau mais alto de performance institucional em termos de efetividade social e ambiental.

\section{Processo de governança: arquitetura institucional e mecanismos}

Após levantar dimensões de análise que rementem às relações de poder e à questão agente-estrutura, bem como apontar elementos de análise relativos aos

15 Schroeder, referido em < http://www.iap2.org/associations/4748/files/IAP2\%20Spectrum_vertical.pdf > . 16 < http://www.iap2.org/associations/4748/files/IAP2\%20Spectrum_vertical.pdf >, Acesso em: 18/08/2016. 
atores e agentes da governança do clima, faz-se necessário identificar e analisar como o processo de governança se desenvolve. Para tal, é preciso definir e caracterizar o que alguns estudiosos definem como arquitetura(s) institucional(is) (BIERMANN et al., 2009). Arquitetura institucional diz respeito à forma como princípios, normas, regras, procedimentos e organizações são arranjados e se relacionam entre si. Outra dimensão importante da análise são os mecanismos e arranjos construídos entre os atores. Alguns autores apontam para redes de governança (PATTBERG, 2010). Outros identificam formas de governança policêntrica (OSTROM, 2010). Biermann, Pattberg e Zelli (2010) argumentam que novos mecanismos de governança do clima têm surgido com atores públicos e privados. Mais especificamente, podem-se identificar redes de governança (PATTBERG, 2010) ou formas de governança policêntrica (OSTROM, 2010a, 2010b).

\section{Arquiteturas de governança: fragmentação e integração}

Arquitetura de governança global é definida por Biermann et al. (2010) como o arcabouço amplo de instituições públicas e privadas, isto é, organizações, regimes e outras formas de princípios, normas, regulações e procedimentos de tomada de decisão que são válidos ou ativos numa determinada área (issue area) da política mundial. Arquitetura pode ser definida como o metanível da governança, no entanto, o foco numa área (issue area) torna o conceito mais estreito do que o de ordem, embora ambos compartilhem um foco no arcabouço geral de governança, que vai além de regimes singulares. A noção de ordem se refere ao sistema de relações internacionais como um todo e a de arquitetura é mais apropriada para áreas distintas de governança global. Ordem é um conceito com viés mais otimista. Arquitetura é mais "neutro" e, por isso, também considera efeitos disfuncionais e não pretendidos (BIERMANN et al., 2010, p. 16) ${ }^{17}$.

Biermann et al. (2010) afirmam que a fragmentação é uma característica geral das arquiteturas de governança global. A utilização dessa noção permite a comparação entre domínios de políticas diferentes. Muitos domínios de políticas ${ }^{18}$ nas relações internacionais não são muito regulados, e frequentemente não dominados por um único regime internacional no sentido tradicional. Outros domínios são, ao contrário, caracterizados por um patchwork de instituições internacionais, que são diferentes em seu caráter (organizações, regimes e normas

17 Tradução livre da autora.

18 No original em inglês: policy domains. 
implícitas), suas constituencies (pública e privada), escopos espaciais (do bilateral ao global) e matérias substantivas (de campos políticos específicos a preocupações universais). Essa situação corresponde à noção de arquiteturas de governança fragmentadas. Na perspectiva dos autores, o processo de governança do clima pode ser caracterizado por uma arquitetura fragmentada.

Ao constatar que as arquiteturas são em geral fragmentadas, Biermann et al. (2010, p. 17) enfatizam três pontos. Primeiro, o termo fragmentação é utilizado como um conceito relativo, ou seja, supõe-se que todos os arranjos são fragmentados em algum grau, assim, consistem em partes distintas, que raramente, ou quase nunca, são totalmente interligadas e integradas. Arquiteturas não fragmentadas e universais são teoricamente possíveis de serem concebidas como opostas à fragmentação; uma arquitetura seria universal se todos os países relevantes naquela área temática estivessem sob o mesmo marco regulatório; participassem do mesmo processo decisório e concordassem com um núcleo comum de compromissos. Empiricamente, tal situação é difícil de visualizar na política mundial contemporânea. Segundo, o uso dos conceitos de arquitetura e de fragmentação não implicam um juízo de valor, não se pressupõe que haja um estado a priori de ordem universal, ou uma tendência universal em direção à ordem, nem que haja um arquiteto. Na maior parte dos casos empíricos, arquiteturas resultam de processos incrementais de institucionalização, decentralizados e raramente planejados. Terceiro, pesquisas empíricas sobre fragmentação de arquiteturas de governança global dependem da escala percebida do problema. Quanto maior a escala percebida do problema, maior o grau de fragmentação provável (BIERMANN et al., 2010, p. 17).

Além disso, Biermann et al. (2010, p. 18) propõem uma tipologia de fragmentação para analisar as arquiteturas de governança em termos de três características: a) grau de aninhamento institucional ${ }^{19}$ e sobreposições entre sistemas de tomada de decisão, ou seja, se o arranjo institucional é baseado em uma única instituição-chave, com outras instituições fortemente integradas, ou se ele se organiza em torno de algumas instituições-chave com outras instituições frouxamente integradas, ou, então, constitui-se de instituições não relacionadas; b) existência e grau de conflitos entre as normas institucionais; c) tipo de constelação de atores. Com base nessas três características, eles apresentam três tipos de fragmentação (BIERMANN et al., 2010, p. 18-19):

19 No original em inglês: institutional nesting. 
1) sinergética, em que as instituições do núcleo incluem quase todos os países e provêm arranjos gerais detalhados e efetivos (círculos concêntricos - por exemplo, arquitetura de governança do ozônio);

2) cooperativa, quando uma área se caracteriza por: i) diferentes instituições e processos decisórios frouxamente integrados; ii) a instituição central não compreende todos os países que são importantes naquela área; e iii) a relação entre normas e princípios de diferentes instituições é ambígua. Apesar dessas três características, a integração geral na arquitetura da governança da área é suficiente para evitar conflito aberto. Assim, políticas na mesma área são definidas, decididas e motivadas por meio de diferentes instituições: de um lado, as centrais; e, de outro, países individuais, que não são parte dessa instituição. Porém, a integração global na arquitetura de governança na área é suficiente para prevenir conflitos abertos entre instituições diferentes. Exemplo, relação entre UNFCCC e o Protocolo de Kyoto.

3) fragmentação conflitiva se caracteriza por diferentes instituições que são: a) pouco conectadas e/ou têm processos de tomada de decisão diferentes ou não relacionados; b) têm conjuntos conflitantes de princípios, normas e regras; e c) têm membresias diferentes e/ou são dirigidos por coalizões de atores, que aceitam, ou mesmo estimulam esses conflitos. Exemplo: regulação de acesso e repartição de benefícios de recursos genéticos: dois regimes tentam regular essa questão, a Convenção sobre Diversidade Biológica e o TRIPS (Agreement on Trade-Related Aspects of Intellectual Property Rights), sob a Organização Mundial do Comércio.

A noção de arquitetura de governança e os tipos de fragmentação apresentados se aproximam da perspectiva de Keohane e Victor (2010) sobre complexo de regimes, que propõem um contínuo para localizar regimes (integrado, complexo, aninhados e desintegrados). Contudo, tal perspectiva, além de não considerar múltiplos atores e níveis, não permite análises comparativas, como proposto por Biermann et al. (2010) com a criação de uma tipologia de fragmentação. Além disso, o conceito de complexo de regimes não leva em conta conflitos nem a forma como os atores da constelação intencionalmente buscam fragmentar a arquitetura de governança. Biermann et al. (2010, p. 21) argumentam que a fragmentação da arquitetura de governança do clima é intencional. Assim, por exemplo, a Parceria Ásia-Pacífico (APP) e propostas similares, patrocinadas pelos EUA, foram criadas não por ignorar o regime do clima, mas por causa dele. 
A perspectiva de arquiteturas de governança (BIERMANN et al., 2010) contribui para visualizar, relacionar e analisar todas as instituições internacionais que regulam uma determinada área. Ao considerar as arquiteturas como fragmentadas e definir tipos de fragmentação, essa perspectiva contribui para avançar na construção de um marco analítico para governança do clima, porém, por partir da noção de áreas temáticas ${ }^{20}$, corre o risco de ser limitadora se não considerar as interações entre domínios políticos diferentes como, por exemplo, as interações entre clima, economia e segurança.

\section{Redes de governança}

Pattberg (2010, p. 146-148) aponta para a formação de redes de governança do clima, que operam sob lógicas diferentes quando comparadas com outros tipos de organizações sociais, como mercados e hierarquias. Redes são definidas como interconexão de três ou mais entidades comunicantes. Seus componentes estruturais incluem indivíduos e organizações e, seus processos, comunicação e formas mais gerais de troca. Ele classifica as redes de governança em três tipos fundamentais, de acordo com as categorias de atores envolvidos: primeiro, redes públicas, que excluem o Estado como um ator unitário central; segundo, redes híbridas de atores da esfera pública e privada; terceiro, redes totalmente privadas, que incorporam lógicas pró-lucro, ou sem fins lucrativos. Ademais, o autor vai além da noção de que políticas públicas são responsabilidade unicamente de governos. Governança em rede é vista como um complemento, ou inovação gradual, de formas mais antigas de fazer política.

De acordo com Pattberg (2010, p. 147), o conceito de redes de políticas ${ }^{21}$ se refere à produção de políticas públicas por meio de interações relativamente estáveis e definidas de atores divergentes numa área política específica, ou seja, arranjos de governança policêntricos, que integram interesses em competição de atores numa estrutura horizontal. Assim, redes de governança climática, que reúnem empresas, sociedade civil e governos em um arranjo, combinam lógicas que normalmente se supõem separadas e transcendem a política ${ }^{22}$ centrada no Estado e baseada em territórios (PATTBERG, 2005, apud OKEREKE et al., 2009, p. 66).

\footnotetext{
20 No original em inglês: issue area.

21 No original em inglês: policy networks.

22 No original em inglês: politics.
} 


\section{Governança policêntrica}

A abordagem de fragmentação da arquitetura de governança (BIERMANN et al., 2010) pode ser complementada pela noção de governança policêntrica de Ostrom (2010). A autora propõe uma noção de governança de common pool resources (CPR) ${ }^{23}$, além do Estado e do mercado. Ostrom (2010a) questiona as teorias de governança, que se baseiam nos dilemas de ação coletiva ou dilemas sociais. Essas teorias partem da noção de ator racional e defendem a necessidade de um ator externo (governo) para impor regras, ou seja, um agente central para ajudar a superar a tendência do ator racional à não cooperação. Com base em experimentos/simulações e pesquisa empírica extensa, Ostrom (2010a) constata que em várias localidades ao redor do globo os casos de auto-organização dos usuários de CPRs evidenciam uma forma de governança que Ostrom denomina policêntrica. Ostrom (2010) acredita que indivíduos, em determinados contextos de interação, podem superar dilemas sociais e construir arranjos de governança de CPRs. Assim, a noção de governança policêntrica implica a existência de muitos centros de decisão que são formalmente independentes.

Na perspectiva da autora (OSTROM, 2010a, p. 653), além do contexto da interação, o que faz diferença é o desenho institucional. Ela elenca alguns tipos de regras dos arranjos locais de governança de CPR que devem estar presentes: definição dos usuários ${ }^{24}$, fronteira dos recursos, congruência com condições locais, apropriação e provisão, arranjos de escolha coletiva, monitoramento dos usuários, monitoramento dos recursos, sanções gradativas, mecanismos de soluções de conflitos, reconhecimento mínimo de direitos, empreendimentos aninhados.

Ostrom (2010b), em outro estudo, propõe uma abordagem alternativa para tratar a problemática da mudança do clima com base na noção de governança policêntrica. De acordo com a autora (2010b), políticas adotadas somente numa escala global não devem gerar confiança suficiente entre cidadãos e firmas, de forma que a ação coletiva possa acontecer para reduzir efetivamente o aquecimento global. Ostrom (2010b) acredita que não se pode esperar uma solução mundial única para a questão climática, nem que um único país, por mais rico que seja,

23 Common-pool resources (CPR) são aqueles que compartilham o atributo de subtractibilidade com bens privados e a dificuldade de exclusão com bens públicos. Florestas, sistemas hídricos, pesqueiros e a atmosfera global são todos CPR de grande importância para a sobrevivência de humanos na Terra. (OSTROM; OSTROM 1977 apud OSTROM 2010a, p. 645).

24 No original em inglês: user boundaries. 
possa resolver a questão. Sua maior crítica está na longa espera por (e a ênfase excessiva em) uma solução global, como se fosse o único caminho a percorrer. Para a autora, soluções globais negociadas no nível global, se não foram sustentadas por uma variedade de esforços nacionais, regionais e locais, não devem funcionar (OSTROM, 2010b, p. 4). Assim, Ostrom (2010b, p. 13-14) advoga o foco em múltiplas escalas, considerando os benefícios globais gerados por ações locais para reduzir emissões.

Em suma, a dimensão analítica que foi discutida refere-se aos princípios, normas e regras acordados e às formas como os diversos atores e agentes interagem, tomam decisões, dividem tarefas e responsabilidades e constroem parcerias através de diversos níveis: subnacional, nacional, transnacional, regional e internacional - do local ao global. A emergência de múltiplos atores resulta em novos arranjos institucionais, ou arquiteturas de governança global do clima. Pode-se apontar também para mecanismos, redes ou governança policêntrica.

\section{Conclusões}

As várias perspectivas sobre governança global do clima fornecem elementos para a análise de arranjos estatais, não estatais e híbridos, em múltiplos níveis, para responder às mudanças do clima. Este artigo buscou fornecer um esquema analítico que combina elementos de correntes teóricas, ou programas de pesquisa diversos, ou seja, uma abordagem epistemológica pragmática e metodologicamente próxima ao ecletismo analítico (FRIEDRICHS; KRATOCHWIL, 2009). Trata-se de um marco em construção para analisar processos de governança climática, com a consciência de que tal marco será sempre provisório.

Desse modo, para analisar respostas diversas à problemática da mudança global do clima, é importante considerar a dimensão do poder e suas múltiplas escalas. Propôs-se uma perspectiva de poder em termos constitutivos, sua natureza múltipla e a diferenciação entre soberania e governos como formas distintas de exercer poder (OKEREKE et al., 2009). Essa consideração de poder permite analisar mecanismos, técnicas e procedimentos específicos de governança climática, além de buscar compreender as escolhas por determinadas alternativas em detrimento de outras. Leva, ainda, a reconhecer as assimetrias e interesses conflitantes dos atores, sem, contudo, atribuir medidas de poder e resultados políticos previsíveis. Trata-se de reconhecer que as estruturas limitam ou condicionam as alternativas e possibilidades dos atores, porém, não as determinam, havendo margem para 
mudanças. Além disso, ao analisar as relações de poder através de níveis e escalas, compreendem-se melhor questões relativas a espaços, lugares, posições e tempo.

Quanto aos atores, ou agentes, é importante atentar para a formação dos três tipos de redes de governança do clima, propostas por Pattberg (2010): redes públicas, que excluem o estado como um ator unitário central; redes híbridas de atores da esfera pública e privada; redes totalmente privadas, que incorporam lógicas pró-lucro e sem fins lucrativos. Essas, segundo o autor, refletem a transformação do processo de formulação e implementação de políticas públicas nas sociedades modernas, em que aumenta a autonomia subsistêmica no interior do estado nação. Além disso, a distinção entre atores e agentes e a noção de graus de agência (SCHROEDER, 2010), bem como as categorias de tarefas de governança propostas por Avant et al. (2010), são úteis para a análise empírica dos processos de governança do clima.

Poder e agência resultam em arranjos institucionais diversificados. A tipologia proposta por Biermann et al. (2010) pressupõe que todos esses são fragmentados. Assim, a tipologia de fragmentação dos autores contribui com a análise por considerar três características-chave: a relação entre as instituições formais, os conflitos entre suas normas e a constelação de atores. Isso leva a identificar o caráter da fragmentação, se ele se encontra mais marcado por sinergia, cooperação ou conflito. Na mesma direção, porém, dando ênfase ao nível local e à noção de governança policêntrica, Ostrom (2010) argumenta, com base no estudo de uma série de casos e também em simulações, que os dilemas de ação coletiva podem ser superados, sendo que arranjos institucionais bem-sucedidos na governança de CPR dependem do contexto de interação (possibilidade de comunicação e confiança entre os atores) e os tipos de regras estabelecidas: definição dos usuários, fronteira dos recursos, congruência com condições locais, apropriação e provisão, arranjos de escolha coletiva, monitoramento dos usuários, monitoramento dos recursos, sanções gradativas, mecanismos de soluções de conflitos, reconhecimento mínimo de direitos, empreendimentos correlacionados (aninhados).

Por fim, vale lembrar que níveis e escalas dos arranjos de governança são histórica e socialmente construídos, refletem relações de poder constitutivo, assim, ao mesmo tempo, podem limitar ou expandir as possibilidades dos atores. A natureza do problema da governança da mudança global do clima é complexa, por isso, qualquer marco analítico será limitado. Entretanto, faz-se necessário encontrar caminhos para analisar e propor soluções. A escolha dessas categorias de análise reflete considerações normativas, como o reconhecimento da urgência do 
problema, o descompasso entre a ciência e o processo político e a necessidade de participação de múltiplos atores nesse processo. Quanto ao conteúdo das normas e regras, esse deve refletir princípios globais já consagrados, como sustentabilidade, equidade, democracia e transparência, bem como princípios a serem desenvolvidos e negociados, que interrompam o processo de transgressão dos limites planetários e levem a sociedades sustentáveis e pós materialistas.

\section{Referências}

AVANT, Deborah D.; FINNEMORE, Martha, and SELL, Susan S. Who governs the globe? In Avant, Deborah; FINNEMORE, Martha; SELL, Susan S. (ed). Who governs the globe? Cambridge Studies in International Relations 114.Cambridge University Press, 2010. BIERMANN, Frank. 'Earth system governance' as a crosscutting theme of global change research. Global Environmental Change, v. 17, n. 3-4, 2007, p. 326-337. Disponível em < http://www.glogov.org/images/doc/Biermann \% 202007\% 20GEC\% 20Earth \% 20 System \% 20Governance.pdf > . Acesso em: 22 ago. 2016.

BIERMANN, Frank. et al. 2009. Earth System Governance: People, Places and the Planet. Science and Implementation Plan of the Earth System Governance Project. ESG Report 1. Bonn, IHDP: The Earth System Governance Project. 2009.

BIERMANN, Frank, PATTBERG, Phillip and ZELLI, Fariborz. Global Climate Governance Beyond 2012 an introduction. In BIERMANN, Frank; PATTBERG, Phillip; ZELLI, Fariborz (eds). Global Climate Governance Beyond 2012 Architecture, Agency and Adaptation. Cambridge University Press. 2010.

BIERMANN, F. et al. The architecture of global climate governance: setting the stage. In BIERMANN, F. PATtBerG, P., ZELLI, F. Global Climate Governance Beyond 2012. Architecture, Agency and Adaptation. Cambridge University Press. 2010

BIERMANN, F. et al. Navigating the Anthropocene: Improving Earth System Governance. Science, v. 335, n. 6074, 2012, p 1306-1307. Disponível em < http://science. sciencemag.org/content/335/6074/1306 > . Acesso em: 22 ago. 2016.

BULKELEY, Harriet ; BETSILL Michele. Cities and Climate Change: Urban Sustainability and Global Environmental Governance . London and New York : Routledge. 2003. BULKELEY, Harriet; NEWELL, Peter. Governing Climate Change. Global Institutions Series. London and New York: Routledge. 2010

BREITMEIER, Helmut; YOUNG, Oran; ZURN, MichaelAnalyzing International Environmental Regimes. From Case Study to Database. Cambridge and London: MIT Press. 2006. 
BULKELEY, Harriet.-. Reconfiguring environmental governance: Towards a politics of scales and networks. Political Geography, v. 24, n. 8, 2005, p 875-902.

COMMISSION ON GLOBAL GOVERNANCE. Our Global Neighborhood. Report of the Commission on Global Governance. Oxford: Oxford University Press, 1995, 410pp. (ISBN 0-19-827998-1)

DELlAS, Eleni; PATTBERG, Philipp and BETSILL, Michele. Agency in earth system governance: refining a research agenda. International Environmental Agreements: Politics, Law and Economics, v. 11, n. 1, 2011, p 85-98. Disponível em: < http://link. springer.com/article/10.1007/s10784-011-9147-9 > . Acesso em: 22 ago. 2016

FRIEDRICHS, J.; KRATOCHWIL, F.. On Acting and Knowing: How Pragmatism Can Advance International Relations Research and Methodology. International Organization 63, Fall, 2009, p 701-31.

GUPTA, Joyeeta. The Problem of Scale in Environmental Governance. IHDP Update. Newsletter of the International Human Dimensions Programme on Global Environmental Change, 1.2007

HAAS, Peter. Saving the Mediterranean: The Politics of International Environmental Cooperation (Political Economy of International Change). Columbia University Press, 1992, $288 \mathrm{p}$.

HAAS, P.M; SPETH, J.G. Global Environmental Governance: Foundations of Contemporary Environmental Studies. Island Press. 2006. 192 p.

HELD, David et. al. Global Transformations. Politics, Economics and Culture. Stanford, CA: Stanford University Press. 1999.

INOUE, Cristina; PRADO Guilherme. Comparando mecanismos de regimes internacionais.

In: $1^{\circ}$ Encontro Nacional da ABRI, 2006.

INOUE, Cristina. Governance of global climate change in the Brazilian Amazon: the case of Amazonian municipalities of Brasil. Revista Brasileira de Política Internacional, v. 55, special edition, 2012, p. 170-189.

KEOHANE, Robert O. and David G.Victor The Regime Complex for Climate Change. Discussion Paper 2010-33, Cambridge, Mass.: Harvard Project on International Climate Agreements, January. 2010.

KRASNER, Stephen D. Structural causes and regime consequences: regimes as intervening variables. International Organization. v. 36, n. 2, 1982, p. 1-21.

LEBEL, L.; GARDEN, P.; IMAMURA, M.The politics of scale, position, and place in the governance of water resources in the Mekong region. Ecology and Society, v. 10, n. 2, art 18, 2005. Disponível em: < http://www.ecologyandsociety.org/vol10/iss2/art18/ > . Acesso em: 22 ago. 2016. 
LEVY, M. A., YOUNG, O. R., \& ZURN, M. The study of international regimes. European Journal of International Relations, v. 1, n. 3, 1995, p. 267-330.

OKEREKE, Chukwumerije; BULKELEY, Harriet; SCHROEDER, Heike. Conceptualizing Climate Governance Beyond the International Regime. Global Environmental Politics v. 9, n. 1, 2009, p. 58-78.

OSTROM, Elinor. Beyond Markets and States: Polycentric Governance of Complex Economic Systems. American Economic Review, v. 100, n. 3, 2010, p. 641-672. 2010a, Disponível em: <https://www.aeaweb.org/articles?id=10.1257/aer.100.3.641 > . Acesso em: 22 ago. 2016.

OSTROM, Elinor. A Polycentric Approach for Coping with Climate Change. Background Paper to the 2010 World Development Report. Policy Research Working Paper 5095. 2010b.

PATERSON, Matthew; HUMPHREYS, David; PETTIFORD, Lloyd. Introduction. Conceptualizing Global Environmental Governance: From Interstate Regimes to Counter-Hegemonic Struggles. Global Environmental Politics, v. 3, n. 2, 2003, p. 1-10.

PATTBERG, P. The role and relevance of networked climate governance. In BIERMANN, F. PATtBerG, P., ZELli, F. Global Climate Governance Beyond 2012. Architecture, Agency and Adaptation. Cambridge University Press. 2010.

PAINEL BRASILEIRO DE MUDANÇAS CLIMÁTICAS, 2013. Mitigação das Mudanças Climáticas: Contribuição do Grupo de Trabalho III do Painel Brasileiro de Mudanças Climáticas ao Primeiro Relatório da Avaliação Nacional sobre Mudanças Climáticas. BARATA, M. M. L. (et al, org.) [Bustamante, M.M.C., ROVERE, E. L. L;. (eds.)]. COPPE. Universidade Federal do Rio de Janeiro, Rio de Janeiro, RJ, Brasil, 405 pp. ISBN: 978-85-285-0207-7.

RAUSTIALA, Kal; VICTOR, David, .The Regime Complex for Plant Genetic Resources. International Organization, v. 58, n. 2, 2004, p. 277-310.

ROCKSTRÖM, J. et al. Planetary Boundaries: Exploring the Safe Operating Space for Humanity. Ecology and Society, v. 14, n. 2, art. 32, 2009. Disponível em: < http://www. ecologyandsociety.org/vol14/iss2/art32/ > . Acesso 22 ago. 2016.

ROSENAU, James N... Governança, ordem e transformação na política mundial, Cap 1. In: ROSENAU, James N. / CZEMPIEL, Ernst-Otto (org). Governança sem governo, ordem e transformação na política mundial, Brasília: Editora UnB. 2000

SCHROEDER, Heike. Agency in international climate negotiations: the case of indigenous peoples and avoided deforestation. International Environmental Agreements: Politics, Law and Economics, v. 10, n. 4, 2010, p. 317-332. Disponível em: < http://link. springer.com/article/10.1007/s10784-010-9138-2 > . Acesso em: 22 ago. 2016. 
STEANS, Jill. Global Governance: a Feminist Perspective. In HELD, D.; MCGREW, A. (ed) Governing Globalization. Power, Authority and Global Governance. Polity Press. 2004. STOKKE, Olav. Regimes as Governance Systems. In: YOUNG, Oran. Global Governance: Drawing Insights from the Environmental Experience. Cambridge, Massachusetts; London, England: MIT Press. 1997.

STRIPPLE, J. \& Pattberg, P. 2010. Agency in global climate governance: setting the stage. Biermann, F. Pattberg, P., Zelli, F. Global Climate Governance Beyond 2012. Architecture, Agency and Adaptation. Cambridge University Press.

VIOLA, E., FRANCHINI, M., RIBEIRO, T.L.. Sistema Internacional de Hegemonia Conservadora. Governança Global e Democracia na Era da Crise Climática. Editora Anna Blumme. São Paulo, 2013.

WETTESTAD, Jorgen. Designing Effective Environmental Regimes. The Conditional Keys, Chelteham, UK; Northhampton, MA: Edward Elgar Publishing, 1999.

YOUNG, Oran (Ed.) (2ed.) Global governance: drawing insights from the environmental experience. Cambridge: MIT Press, 2000. 